\title{
Study on the joint training mode of optical engineering master
}

Jicheng Wang, Zheng-Da Hu, Tian Sang, Shumei Gao, Guoqing Chen

Jicheng Wang, Zheng-Da Hu, Tian Sang, Shumei Gao, Guoqing Chen, "Study on the joint training mode of optical engineering master," Proc. SPIE 10452, 14th Conference on Education and Training in Optics and Photonics: ETOP 2017, 104524W (16 August 2017); doi: 10.1117/12.2269419

SDIE Event: 14th Conference on Education and Training in Optics and Photonics, ETOP 2017, 2017, Hangzhou, China 


\title{
Study on the joint training mode of optical engineering master \\ Jicheng Wang*, Zheng-Da Hu, Tian Sang, Shumei Gao*, Guoqing Chen \\ School of Science, Jiangnan University, Wuxi, China, 214122 \\ *jcwang@jiangnan.edu.cn; smgao@jiangnan.edu.cn
}

\begin{abstract}
We study on the joint training mode of optical engineering (OE) master in the ways of teaching, scientific research and practice cooperation. Our goal is to enhance the abilities and research level of OE graduate students by establishing the joint training cooperation with the domestic or foreign high level universities, the top research institutes and the famous enterprises, and to let more and more graduate students enter the high level universities and companies. In addition, we want to create the training quality evaluation index and evaluation system of the $\mathrm{OE}$ master students to evaluate this joint training mode.
\end{abstract}

Keywords: optical engineering, joint training mode, training quality evaluation index, evaluation system

\section{THE CONNOTATION OF JOINT TRAINING MODE}

1.1 International joint training mode of graduate students

1.1.1 The connotation of international joint training mode of graduate students

As the name implies, international joint training mode of graduate students is that different countries and regions joint to cultivate graduate students, according to the advantage of talents and teachers, equipment of two sides or multi。 This way of cooperation has the joint training between international colleges and universities, between universities and intermediaries and between schools and enterprises. At present the inter-school co-cultivation is one of the most important way in the domestic. In the context of economic globalization, talent competition is also gradually globalization, which requires that the graduate education system at the top of the education system should also adapt to international competition. And international joint training is an effective means to achieve this goal. The main advantages are:

1) Learn from and introduce advanced educational ideas and educational modes, which is beneficial to the reform and innovation of the graduate education in China.

2) To promote the cultivation of international talent, with the rapid development of economic globalization and the importance of knowledge-based economy, our country needs a large number of the high-level talents who can master proficiently professional skills and understand the national conditions, laws and cultural. Sending students to foreign countries and developing Chinese-foreign Cooperation in running schools of graduate education are all effective way to cultivate those talents.

1.1.2 Analysis on the international joint training mode of graduate students

The international joint training mode of graduate students is a new thing in the field of education after China 's reform and opening up, which plays a positive role in introducing foreign quality education resources, learn from foreign useful teaching and management experience, accelerating the pace of China's educational reform and development, promoting international exchanges and cooperation in China's education, and increasing the diversity and selectivity of China's educational supply. Specifically, it has the following advantages:

1) It introduces advanced educational philosophy and education mode

2) It is beneficial to the reform and innovation of graduate education in China. The implementation of the joint training of graduate students can introduce new professional disciplines and original textbooks and the mutual flow of teachers and students, learn educational ideas and training modes from developed countries and speed up the development of graduate education in China.

3) It is beneficial to the cultivation of international talents in China. With the rapid development of economic globalization and the importance of knowledge economy, our country needs a large number of the high-level talents who can master proficiently professional skills and understand the national conditions, laws and cultural. Sending students to foreign countries and developing Chinese-foreign cooperation in running schools of graduate education are all effective way to cultivate this talents.

4) Chinese - foreign cooperation in running schools is beneficial to the improvement and norm of the management system. Partners who have high-level teaching and academic research often have perfect the educational administration 
system. In the process of cooperation in running schools, we can find out shortcomings, according to our country's existing management mode, and we can study and learn from the management mode of foreign developed countries in order to make our country's management system of higher education more standardized and international.

However, for now there are still some areas to be improved in the international joint training of graduate students, which is mainly reflected in the following aspects:

1) Teaching system and school orientation is not clear。This is mainly caused by the unequal education and teaching system between joint training countries

2) The recognition work of foreign education is serious. For Chinese and foreign joint training graduate students, AS mutual recognition work is in progress between China and some countries, therefore, the Chinese-foreign cooperation in running schools always faces the embarrassing situation that foreign education cannot be recognized.

1.2 School and enterprise joint training mode of graduate students

1.2.1 The connotation of school and enterprise joint training mode of graduate students

School-enterprise cooperation includes two meanings. First, it is an organic combination of education and industry between the two relatively independent departments. It is combined on the basis of increasing social division of labor, modern large-scale production and Technological development. And it is necessary to follow the law of their own development of education, but also to follow the laws of production and economic development. Second, schoolenterprise cooperation is a combination of two - way active participation, Colleges and universities need the equipment and capital of enterprises, enterprises rely on the university's science and technology, knowledge and talents. Schoolenterprise cooperation, its essence is to make the social, production integrate into higher education, in order to form Interdependence, mutual promotion, complementary advantages, inseparable organic whole.

1.2.2 Analysis of school and enterprise joint training mode of graduate students

The school and enterprise joint training mode of graduate students is the integration of industry companies, universities, and research institute with the graduate school to joint training the graduate students. It has the following advantages in practice:

For graduate students, the school and enterprise cooperation is beneficial to improve students' innovation ability, practical ability and employment competitiveness. Currently, many companies clearly require the graduate students with strong profession quality, comprehensive and practical work abilities, and relevant work experience in the recruitment information. There is no doubt that school and enterprise cooperation can solve the drawbacks of single schools to cultivate graduate students.

For colleges and universities, they can take full advantage of the enterprise information advantages, including market demand information, practical technical information and so on. Enterprises should provide the information in time and the school should pay full attention to and take full advantage of the information, which are the premise of sincere cooperation and substantive cooperation. As described above, the importance of career ability is to obtain market information, and to adjust the innovation ability of production structure and product technology performance according to market demand and scientific and technological progress. Only both parts give full playing to the advantages of enterprises information, and to determine or timely adjust professional settings, training objectives, it is possible to cultivate high-quality, strongly skillful talents who can really adapt to demand for social and economic development. This combination has a positive meaning and practical value and can give full play to the technological advantages of enterprises. Enterprises gather a large number of practical technical talents for production and service frontiers, and it is possible that market demand, new technology, new technology convert into new products through their smart brain, smart hands, which can make up for the defect of inadequate school education practice

For the enterprise, Enterprises can make full use of the intellectual resources of colleges and universities to promote enterprise research and development, and can obtain more senior talents in their own companies. Through school and enterprise joint training, graduate students who do not need more vocational training can quickly bring benefits for enterprises, which can save the cost of enterprises human resource development. Many problems are exposed in the practical process of school and enterprise joint training of graduate students.

In the cooperation between universities and enterprises, there are some differences between the two sides, such as different cultural backgrounds, targets and values. This will result in a lack of cooperation power. Security system is imperfect. In the process of mutual cooperation between universities and enterprises, it is difficult to protect the rights and interests of both parties in the form of law while meeting problems related to the intellectual property rights and the technical value. 
1.3 Interscholastic joint training mode of graduate students

1.3.1 The connotation of interscholastic joint training mode of graduate students

In this paper, the joint training mode mainly refers to the cooperation between colleges and universities or colleges and research institutes. Because of the different emphasis on the discipline construction in the domestic universities, each university has its own advantage discipline and characteristic specialty. However, the modern education requires the students to have comprehensive quality and interdisciplinary quality. Therefore, if the educational resources between colleges and universities can be shared and the course and scientific research can be cooperated, it will provide great convenience for students' way to success.

1.3.2 Analysis on the interscholastic joint training mode of graduate students

The interscholastic joint training mode of graduate students has the following advantages:

1) It is beneficial for each training unit to play their respective advantages, and build up a common platform for the cultivation of innovative talents.

2) It is conducive to the scientific research and academic exchanges between universities and colleges, and is conducive to promoting the construction of a reasonable disciplinary structure in Colleges and universities.

3) It is conducive to the rationalization of China's higher education, to better meet the needs of market economy and the development of harmonious society. Interscholastic joint training is an important way to overcome the drawbacks of China's higher education management system and develop higher education.

Government education departments should vigorously promote and promote joint training work, and improve the corresponding policies and regulations.Each joint training unit should play their own running school autonomy, innovation and joint training mechanism base on equality and students' benefit.

\section{CURRENT SITUATION AND TREND ANALYSIS}

In the developed countries in Europe and America like United States, Britain and Germany, Professional degree graduate training started earlier. In 1904, the United States proposed a plan to train a large number of practical professionals. The formation period of its professional degree graduate training is from the beginning of the 20th century to 1945.It became a rapid development stage from 1945 to 1970, and has entered a mature period since 1971. At present, professional graduate students have become the main body of postgraduate education in western developed countries. There are nearly 400 kinds of full-time masters in the United States. The full-time master's degree conferred in 2006 was $63.7 \%$ in the United States and $15 \%$ in Britain of the total master's degree. After a long period of exploration, practice and innovation, the United States has formed a complete and high-quality full-time professional graduate education system, via its strict access system, career-oriented training objectives, a high level of teachers, professional and impartial quality control.

China's professional degree graduate training began in 1984. Only part of the university put forward the training of engineering type master's proposal at that time. In 1988, the concept of "professional degree" was proposed. In 1990, the ninth session of the Academic Degrees Committee of the State Council modified the "professional degree" as "professional degree". Since 1991, China has officially carried out professional degree education. From 1984 to 1995, it was the start-up stage of the cultivation of professional degree graduate students in China. It became the development stage from 1996 to 2008. In March 2009, the Ministry of Education issued the "Notice of the Ministry of education on the arrangement of the 2009 full time professional degree graduate student enrollment plan" and "Some opinions of the Ministry of education on the training of full time master degree graduates". It is clearly stated that the full-time master's degree especially the full-time undergraduate graduates must be increasingly enrolled and the full-time master's degree graduate education must be carried out to better adapt to national economic construction and social development's urgent need for high-level applied talents and actively develop professional degree education with Chinese characteristics. This marks an important change in the development of the master's degree education in China from the cultivation of academic talents to the training of applied talents. "Outline of the National Medium and Long Term Education Reform and Development Plan (2010-2020)" clearly states: "Focus on expanding the training scale of application type, compound type and skilled type personnel, and accelerate the development of professional degree graduate education". Since then, China's professional degree graduate education entered a rapid development stage.

Because of the late start of postgraduate education in China, especially the hasty start of the full-time professional degree graduate training, the relevant theoretical research and practical exploration are relatively weak and pilot practice and experience are lacked. There are many other issues, such as low social recognition and the quality of students, inaccurate target, the similar training mode to the academic type and uncertain employment prospects for graduates. All of them will affect and restrict the steady and healthy development of the work on training full-time professional degree graduate students. 
The development of full-time master's degree is a focus of current and future graduate education, but China's fulltime degree of postgraduate education is still in its infancy. The training objectives, teaching ideas, curriculum, teaching content, teaching methods, management system, quality standards and evaluation mechanism of full-time professional masters are to be studied, explored and practice. At present, the exploration of full time professional master training mode has become a hot topic in China's graduate education, which will have a profound impact on the development of graduate education in china.

The Europe countries, the United States and other developed countries have been developed in this area for a long time and accumulated a lot of experience. The United States universities perform the joint graduate training started much earlier. Through the effective combination with universities, research institutes and enterprises, it has trained a large number of high-level applied talents for the society, and promoted the rapid development of American social economy today. In order to ensure the teaching quality, the United States only enrolls students whose grade reach or exceed to excellent level. The training period in the United States training is from one to five years, usually two years. The course is divided into compulsory courses, professional courses, seminars and exercitation. Curriculum includes basic theoretical knowledge and professional knowledge, focusing on practical training content. The structure is relatively reasonable. The teaching method is mainly based on the case and the seminar analysis, emphasizing the combination of theory and practice. The level of teachers' security is high. Many senior engineers in the research institutes, enterprises often do part-time jobs in the university. In the quality evaluation of graduate students, the United States has established a strict supervision system. The quality of the school and its staff is strictly evaluated through the qualification authentication system, social assessment system and professional qualification certificate system. These measures effectively guarantee the quality of master training.

The education of the European countries is mainly represented by Germany. Graduate enrollment in Germany has a higher requirement on the master's academic performance during the graduate period, especially for the students of higher professional colleges and even close to harsh level, to reach and even exceed the excellent level. In addition, in the interviewing with students, the quality of students' scientific research and practical ability need to be understood, and qualified students are still facing the possibility of being eliminated. For training style, Germany universities does not have a specific training period, curriculum and specific teaching methods, but the completion time of the paper is used to determine the length of training, The selected direction of the thesis indicates the direction for the study of the course by scientific research activities, mentor guidance, regular participation in the study class to achieve the professional degree of training objectives. In the protection of teachers, the German tutor selection has a very high demand. Those who have rich experience and high academic level tend to be selected, and then the candidates can be determined according to the comprehensive evaluation. The selection process is very strict, but once selected, the candidate will become a long-life professor. In order to ensure the quality of graduate education, Germany has established an evaluation system based on the general and professional standards. The certificate authority evaluates students and disciplines according to the general standards and professional standards of discipline. The general standard applies to engineering science, informatics, natural sciences and mathematics disciplines, covering a wide range of content. The main assessment index involves training objectives, students' and the market's needs for the profession, professional structure and educational system, professional characteristics, syllabus, teaching methods, human and financial resources and infrastructure, quality assurance measures and examinations and learning rules. Professional standards are different because of the different professional, focusing on evaluating the ability of graduates.

Based on the above analysis, we can see that the United States and Germany have established a complete system for training master. These experiences have a positive guiding significance for the training of master of optical engineering master in china. This study aims to establish the joint training mode of the school, the enterprise and the institute, in order to provide theoretical and practical guidance for some specific and important problems in the current full-time professional master degree postgraduate training, promote the healthy development of the professional degree of graduate education, and meet national economic construction and social development's urgent need for high-level applied talents.

\section{THE IMPORTANT LINK OF JOINT TRAINING MODE}

3.1 The main problem to be solved Graduate education is the highest level of education in higher education, directly related to the development of country's economic, technological and educational. Graduate training mode and quality are important indicators to measure the level of graduate education. In order to cultivate compound, innovative and practical type of senior talents of optical engineering, optical engineering of Jiangnan University recruit graduate students from the beginning of 2007. However, 
through the actual enrollment, training and employment situation over several years, the optical engineering master's training still did not achieve the desired goals.

At present, there are the following problems:

1) Students have weak professional knowledge, and learning, independent research, work ability is low.

2) Research topics are too old, and cannot combine with the frontier scientific research and the actual production demand of effectively.

3) Graduates failed to better adapt to scientific research and the demand of employing units, graduate students training model is single, which restricts the future development of graduate students and restricts graduate students to continue their study.

3.2 The goals to be achieved

In order to solve these problems, While responding to national support for advocacy, This topic will achieve the joint training of optical engineering master through cooperation with domestic and foreign universities, research institutes and well-known companies to promote the reform of graduate training mechanism in colleges and universities, to cultivate the application type, compound type, a shortage of high-level talents that the country needs and enhance the scientific research and practical ability of graduate students, so that graduate students can better meet the needs of social and economic development.

The main goals of this topic as follows:

3.2.1. Research on school-enterprise joint training mechanism of master of Optical Engineering.

1) The construction of a "Research for fruitful production" training goal.

2) The implementation of a "research-academy integration, industry-academy cooperation" scientific research project.

3) The improvement of system of enterprise mentors and industry professing teachers.

3.2.2. Improvement of comprehensive academic assessment mechanism and comprehensive incentive mechanism

1) Improvement of comprehensive academic assessment mechanism

i) The establishment of Comprehensive Evaluation System of Students' Professional Knowledge

ii) The establishment of Students' Engineering Ability Evaluation System

2) Improvement of comprehensive incentive mechanism

iii) Establish a mechanism of joint training graduates' assessment and evaluation reward, and encourage outstanding students to join the teaching links of the joint training

iv) Establish a mechanism for the retention of excellent graduate students with cooperative units, which is beneficial for graduate students' further study and development

3.3 preliminary achievements

Recent years, many graduate students of our school at Jiangnan University have been sent to high level collges such as University of California at Berkeley, Purdue University, University of Illinois, University of California at Davis, Michigan University, University of Newcastle, University of Dayton, Nanyang Technology University, Madrid high school and research center to conduct graduate studies and joint training graduate programs through CSC national visiting scholar (postdoctoral) program, overseas training programs for graduate students of Jiangnan University, CSC national graduate student program and other overseas training programs. We obtain the good effects in the early stage of scientific research, teaching, practice joint training cooperation mode, and have carried out the pilot work of joint training mode with the Purdue University, Newcastle University and other co-operation units [1].

\section{PRACTICAL SIGNIFICANCE AND PROMOTION VALUE}

The practical significance of this topic is to try to establish a joint training mechanism with high-level universities, research institutes and enterprises at home and abroad, it is the need that the optical Engineering promotes the reform of postgraduates' training mode and improves the quality of postgraduate training. The creative ability and practical ability of graduate students can only be cultivated in innovation practice. Organize graduate students into the joint training unit to carry out the scientific research, practice and innovation; strengthen cooperation between the two sides of scientific research, teaching, practice, and learn advanced scientific research and graduate training, management mode from cooperative units through leaning from and communicating with the scientific research, teaching frontiers colleges and universities, research institutes, enterprises in-depth, which is an important measure to carry out the work of graduate education seriously, is an important innovation of the graduate training mode, is an important and effective way for the 
graduate students to strengthen the rigorous scientific research training and earnestly cultivate the innovation ability and practical ability of graduate students.

The value of this topic is to establish a joint training mechanism with high-level universities, research institutes and other cooperative units, which is the need to strengthen industry-university-institute cooperation between universities and universities, to promote the reform of running schools and improve the capability of independent innovation. Deepening the industry-university-institute cooperation between universities and universities is the only way where colleges and universities deepen the school system and the reform of school mode, improve the quality of talent training, independent innovation ability and social service level and enhance the core competitiveness. Organize of graduate teams into the joint training units to exchange, study, enhance the degree of optical engineering master's research, teaching, practical abilities, which is the combination point of universities. Talent training industry-university-institute cooperation between universities and universities and production-study-research cooperation scientific research, is the combination point of the width expansion and depth promoting of the industry-university-institute cooperation between universities and universities.

\section{EMPHASIS AND INNOVATIONS}

\subsection{Emphasis}

1) The target positioning is accurate and runs through the entire training process. All contents of training mode of full-time professional master graduate student must be closely around the overall goal of " cultivating high-level application-oriented talents", guided by practice, focus on the application, and grasp the relevance and differentiation of academic masters. The work of the training process is carried out on how to achieve the overall aims.

2) The program is specific, carrier, operable, controllable, evaluable, and optimized.

3) Theory combined with practice, to be tested, optimized and refined in practice.

5.2 Innovations

1) Establish a new mechanism and new model for co-training of full-time degree master's degree under the cooperation of scientific research, teaching and practice, and get the way and method of establishing the master's training base.

2) Establish the overall framework, mode of operation and regulatory system of the practice for full-time professional degree graduate students' training, and create the expansion and construction of a practical teaching platform.

3) Create a new full-time professional degree graduate students' training quality evaluation index and evaluation system.

\section{PROGRAM DESIGN}

\subsection{Research ideas}

Graduate education is the highest level of education in higher education, which is directly related to the level of development of the country's economy, technology and education. Graduate training mode and qualities are an important index to measure the level of graduate education. In order to solve these problems, and response to the support of the country, this topic will realize the joint training mode of a master 's degree in optical engineering by establishing the scientific research, teaching, practice and cooperative relations with a number of well-known universities, research institutes and enterprises at home to promote the reform of graduate students training mechanism, to cultivate the country needs of the application type, compound type, shortage of high-level talents, so that graduate students can better meet the needs of social science and technology, economic development.

6.2 Methods and Pathways

In order to achieve the goal of joint training of optical engineering masters, It is proposed to formulate a series of complete operation and management system of workstations, including the task allocation system of Jiangnan University and cooperative units, the system of postgraduate term stage allocation, the internal supervision and examination system between tutors of Jiangnan University and Jiangnan University tutor and cooperation unit tutors, so as to ensure the benign, orderly and effective implementation of the joint training of graduate students work.

6.2.1. Research on school-enterprise joint training mechanism of master of Optical Engineering

1) The construction of a "Research for fruitful production" training goal

In order to meet the future needs of scientific research and the actual research and development of the industry in photoelectric professional, combined with the national " The 13th Five-year " plan, Optical engineering will 
truly do "Research for fruitful production" in accordance with the ideas of the scientific frontier development, market demand - research - industrial application, which guides actively the training goal of the master of Optical Engineering on the basic research level.

2) The implementation of a "research-academy integration, industry-academy cooperation" scientific research project

In colleges and universities, scientific research topics provide a guarantee for postgraduate training. In order to combine postgraduate research topics with practical production needs effectively, the vertical, horizontal researches are strived through the effective integration with universities, research institutes, enterprises, which can not only tackle difficulties, but also provide the practical opportunities and more research and employment opportunities for optical engineering graduate students.

3) The improvement of system of enterprise mentors and industry professors teacher

The system of enterprise mentors and industry professional teachers is constantly improved and the goal of optical graduate student joint training of two tutors is achieved through the establishment of enterprise graduate workstations, which makes students obtain the training of two sides tutors' professional knowledge, broaden their horizons, apply their knowledge, become national necessary application type, compound type, shortage type high-level talents.

6.2.2. Improvement of comprehensive academic assessment mechanism and comprehensive incentive mechanism

1) Improvement of comprehensive academic assessment mechanism

2) The establishment of Comprehensive Evaluation System of Students' Professional Knowledge

3) The establishment of Students' Engineering Ability Evaluation System

4) Improvement of comprehensive incentive mechanism

5) Establish enterprise assessment and evaluation reward system

Organize well-known universities at home and abroad, research institutes, enterprises high-level talents to train the optical engineering graduate production theory training regularly, and organize graduate students to various colleges and universities, research institutes, enterprises to visit and study, regularly hold various forms of academic exchange, after the training of graduate students, the technical assessment, reporting scoring system and the corresponding evaluation reward mechanism will be carried out, and implemented.

4) Establish a mechanism for the retention of excellent graduate students in cooperative units

Excellent graduate students will obtain the opportunity to be retained or continue to study, and will sign a graduate employment program in cooperative units.

\section{ACKNOWLEDGMENTS}

This work is supported by the National Natural Science Foundation of China (Grant Nos. 11504139), the Natural Science Foundation of Jiangsu Province (Grant Nos. BK20140167), the Key Laboratory Open Fund of Institute of Semiconductors of CAS (Grant No. KLSMS-1604), Jiangsu Provincial Research Center of Light Industrial Optoelectronic Engineering and Technology (Grant No. BM2014402), and the research and practice program for teaching innovation of graduate education of Jiangnan University.

\section{REFERENCES}

[1] J. Wang, S. Gao, W. Luo, and G. Chen, "Research and exploration of practical teaching in the innovation platforms of optical information science and technology," Phys. \& Eng. 23, 61-64 (2013). 